\title{
Involvement of Macrophage Chemotactic Protein-1 and Interleukin-1 $\beta$ During Inflammatory but Not Basic Fibroblast Growth Factor-Dependent Neovascularization in the Mouse Cornea
}

\author{
Shigeo Yoshida, Ayako Yoshida, Hironori Matsui, Yu-ichiro Takada, and \\ Tatsuro Ishibashi
}

\begin{abstract}
Department of Ophthalmology (SY, AY, TI), Kyushu University Graduate School of Medicine, Fukuoka, Japan; and Department of Ophthalmology \& Visual Sciences (HM, YT), W.K. Kellogg Eye Center, University of Michigan,
\end{abstract} Ann Arbor, Michigan

\begin{abstract}
SUMMARY: Corneal neovascularization develops in several pathologic conditions, but its underlying mechanisms remain elusive. We used a mouse inflammatory corneal model (corneas cauterized with silver nitrate) and assessed the role of monocyte/macrophage-attracting factors, macrophage chemotactic protein-1 (MCP-1), and a proinflammatory cytokine, IL-1 $\beta$, on macrophage recruitment and neovascularization. Both MCP-1, IL-1 $\beta$ protein, and mRNA levels increased markedly 12 hours after the chemical cauterization. In situ hybridization showed that MCP-1 was located in corneal epithelial cells, and IL-1 $\beta$ was located in corneal epithelial cells and infiltrating inflammatory cells. In addition, double staining of corneas with antibodies specific for monocytes/macrophages and IL-1 $\beta$ revealed that IL-1 $\beta$ was found in infiltrating monocytes/macrophages at Day 2 after cauterization. Both IL-1 $\beta$ and MCP-1 induced neovascularization in a rat cornea model, and the cauterization-induced corneal neovascularization was partially inhibited by subconjunctival injection of anti-IL-1 $\beta$ or anti-MCP-1. Coadministration of two antibodies inhibited corneal neovascularization slightly more than that by the administration of each. In contrast, administration of the anti-MCP-1 or anti-IL-1 $\beta$ showed minimal inhibition of basic fibroblast growth factor-driven corneal neovascularization by mouse cornea assay. Cauterized corneas treated with anti-MCP-1 antibody had significantly fewer monocytes/macrophages than control. These results indicate the existence of distinct monocyte/macrophage-involved angiogenic pathways in mouse cornea, in which MCP-1 released from corneal epithelial cells attracts monocytes/macrophages into the cornea, where they release IL-1 $\beta$ leading to inflammatory neovascularization. In addition, the IL- $1 \beta$ and MCP-1 released from the corneal epithelial cells may directly induce corneal neovascularization. (Lab Invest 2003, 83:927-938).
\end{abstract}

$N$ eovascularization is a common feature of inflammatory, infectious, and traumatic diseases of the cornea (Chang et al, 2001; Epstein et al, 1987; Klintworth and Burger, 1983). Although it can occasionally serve a beneficial role in the clearing of infections and wound healing, its disadvantages are numerous. For example, neovascularization is a severely disabling condition resulting in loss of the immunologic privilege of the cornea and can cause an impairment of vision.

To date, the pathogenesis of corneal neovascularization has not been clearly defined, and the identity and significance of the angiogenic growth factors are not fully known. Investigations have supported the hypotheses that corneal neovascularization is a manifestation of an inflammatory response and that leuko-

\section{DOI: 10.1097/01.LAB.0000075642.11787.83}

Received February 18, 2003.

Address reprint requests to: Dr. S. Yoshida, Department of Ophthalmology, Kyushu University Graduate School of Medicine, 3-1-1 Maidashi, Higashi-ku, Fukuoka-city, 812-8582, Japan.E-mail: usyosi@yahoo.com cytes play an essential role in stimulating corneal vascular ingrowth (Dana et al, 1998b; Gan and Fagerholm, 2001; Moromizato et al, 2000; Zhu and Dana, 1999). Among the inflammatory cells, macrophages perform a wide variety of biologic functions including participation in neovascularization (Crowther et al, 2001; Sunderkotter et al, 1994). Polverini et al (1977) have demonstrated that a conditioned medium derived from activated macrophages can induce angiogenesis. In addition, tumor-associated macrophage infiltration is correlated with angiogenesis in individuals with invasive breast cancer (Lewis et al, 2000). These observations suggest that activated monocytes/macrophages may also be involved in corneal inflammatory neovascularization.

The angiogenic potential of cells and substances has been determined in several angiogenic model systems, such as the in vivo corneal micropocket assay (Kenyon et al, 1996; Yoshida et al, 1997, 1998, 1999a, 2003b) and the inflammatory corneal model of neovascularization (Amano et al, 1998; Dana et al, 1998b; Edelman et al, 1999; Ogawa et al, 1999; 
Sunderkotter et al, 1991; Zhang et al, 2002). Using the mouse inflammatory corneal model in which corneas are cauterized with silver nitrate, we have found that angiogenesis is associated with the influx of monocytes/macrophages. This observation demonstrated that the cauterized murine cornea is a useful model for further studies on the role played by monocytes/ macrophages and their cell products in the angiogenic process (Ogawa et al, 1999).

Chemokines, a family of structurally related cytokines involved in the activation and directed migration of immune cells, may be pathophysiologically important mediators of inflammation (Kunkel, 1999). We have previously demonstrated that a chemokine, macrophage inflammatory protein- $1 \alpha$ (MIP-1 $\alpha$ ), which mediates the recruitment of monocytes/macrophages in several inflammatory diseases, is induced during neovascularization in a mouse model of inflammatory corneal neovascularization (Ogawa et al, 1999) and oxygen-induced ischemic retinopathy (Yoshida et al, 2003a). Another well-studied chemokine that is a strong chemoattractant for monocytes/macrophages is monocyte chemotactic protein-1 (MCP-1). MCP-1 mediates the recruitment of monocytes/macrophages in several inflammation models and diseases (Strieter et al, 1996) and can also induce corneal neovascularization (Goede et al, 1999). However, it remains unclear whether MCP-1 plays a role in inflammatory corneal neovascularization.

Recruited monocytes/macrophages can produce a number of growth stimulators and inhibitors, proteolytic enzymes, and cytokines at the site of injury that are capable of modulating new vessel formation (Sunderkotter et al, 1994). TNF- $\alpha$ is an angiogenic molecule produced by monocytes/macrophages and is a likely candidate for an angiogenic regulator during wound healing (Fahey et al, 1990). We have shown that TNF- $\alpha$ may also trigger angiogenesis by inducing IL-8 and vascular endothelial growth factor, as an autocrine or a paracrine, by the corneal micropocket assay (Yoshida et al, 1997). However, in the mouse model of chemical cauterization, the level of TNF- $\alpha$ was not increased by the inflammatory stress, suggesting that TNF- $\alpha$ alone may not have a major role in this model (Ogawa et al, 1999). Alternatively, we hypothesized that IL-1 $\beta$, which shows a striking overlap of biologic activities with TNF- $\alpha$ (Le and Vilcek, 1987), may play an important role in this model because recent studies suggested that IL-1 $\beta$ plays an important role in the regulation of inflammation and wound healing on the ocular surface (BenEzra et al, 1990; Coxon et al, 2002; Dana et al, 1998b; Sotozono et al, 1997; Wilson et al, 2001)

Thus, we have investigated whether the monocyte/ macrophage-attracting proteins, $\mathrm{MCP}-1$ and proinflammatory cytokine IL-1 $\beta$, play a role in attracting monocytes/macrophages and/or inducing neovascularization in a mouse model of corneal neovascularization. Experiments were also performed to determine the cellular sources of these molecules.

\section{Results}

\section{Induction of MCP-1 and IL-1及 in Cauterized Corneas}

We tested for MCP-1 and $\mathrm{IL}-1 \beta$ in the cauterized cornea model because they have been recently reported to play an important role in the pathogenesis of several wound- and inflammation-related models (Boring et al, 1998; Dana et al, 1998b; Gosling et al, 1999; Gu et al, 1998; Low et al, 2001; Sotozono et al, 1997; Yoshida et al, 2003a). The protein levels of MCP- 1 and IL- $1 \beta$ were determined by ELISA with the level of TNF- $\alpha$ protein as a negative control. At 12 hours after cauterization, both MCP- 1 and IL- $1 \beta$ protein levels had increased significantly, then declined markedly by Day 5 (Fig. 1, A and B). MCP-1 protein was not detected in untreated normal corneas, and in contrast, 100 to $200 \mathrm{pg} / \mathrm{mg}$ total protein of IL-1 $\beta$ was observed in the normal corneas. Similar to our earlier results (Ogawa et al, 1999) and those of others (Sotozono et al, 1997), the levels of TNF- $\alpha$ protein were not significantly changed after chemical cauterization (Fig. 1C).

We then performed real-time quantitative RT-PCR (qRT-PCR) analysis of cauterized corneas to quantify the level of MCP-1 and IL- $1 \beta$. Both MCP- 1 and IL-1 $\beta$ mRNA were dramatically increased as early as 12 hours after cauterization (about 120- and 90-fold, respectively), and then the mRNA expressions of both decreased (Fig. 2).

\section{Localization of MCP-1 and IL-1 $\beta$ in Cauterized Corneas by In Situ Hybridization and Immunohistochemistry}

To determine the cellular source of MCP-1 and IL-1 $\beta$ in cauterized corneas, serial sections of cauterized corneal tissues obtained 12 hours after cauterization were subjected to in situ hybridization with antisense or sense riboprobes of equivalent specific activity. In sections of cauterized corneas incubated with antisense riboprobes (Fig. 3B) and with sense riboprobes (Fig. 3C), MCP-1 was predominantly present in corneal epithelial cells, especially in the basal cells (Fig. $3 \mathrm{~B})$. In contrast, IL-1 $\beta$ was observed in both inflammatory cells within the corneal stroma and corneal epithelial cells (Fig. 3E, with antisense riboprobes; Fig. $3 F$, with sense riboprobes). The expression of MCP-1 with antisense riboprobes was weak, if detected at all (Fig. 3A), and that of IL-1 $\beta$ was weakly detected in untreated corneal epithelium (Fig. 3D). Double staining of corneas with antibodies specific for monocytes/ macrophages and $\mathrm{IL}-1 \beta$ revealed that this cytokine was found in monocytes/macrophages at Day 2 after cauterization (Fig. 4, A to C).

\section{Induction of Neovascularization by IL-1 $\beta$ and MCP-1 by Corneal Micropocket Assay}

To determine whether IL-1 $\beta$ and MCP-1 are directly associated with the onset of angiogenesis, we implanted Hydron pellets impregnated with IL- $1 \beta$ or MCP-1 into rat corneas. IL-1 $\beta$ (10 ng) or MCP-1 (50 ng) elicited an angiogenic response, but administra- 
A.

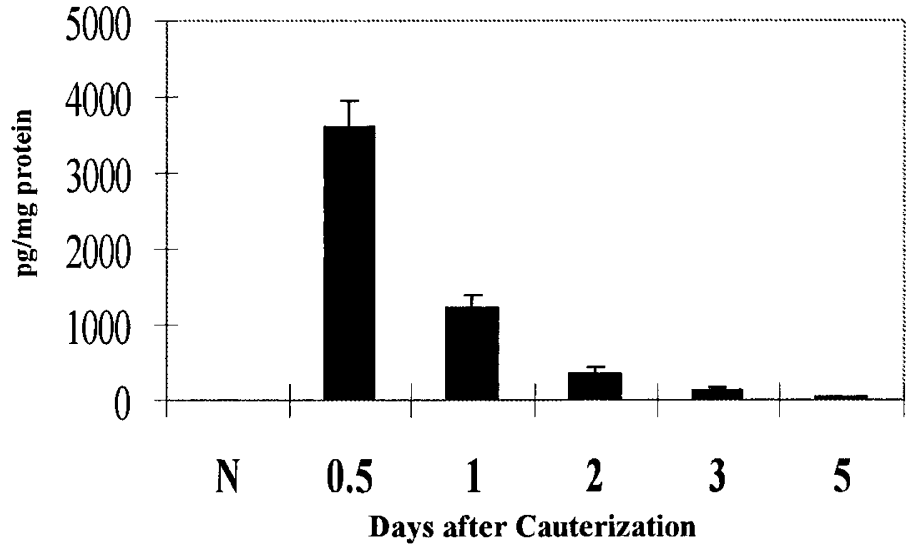

B.
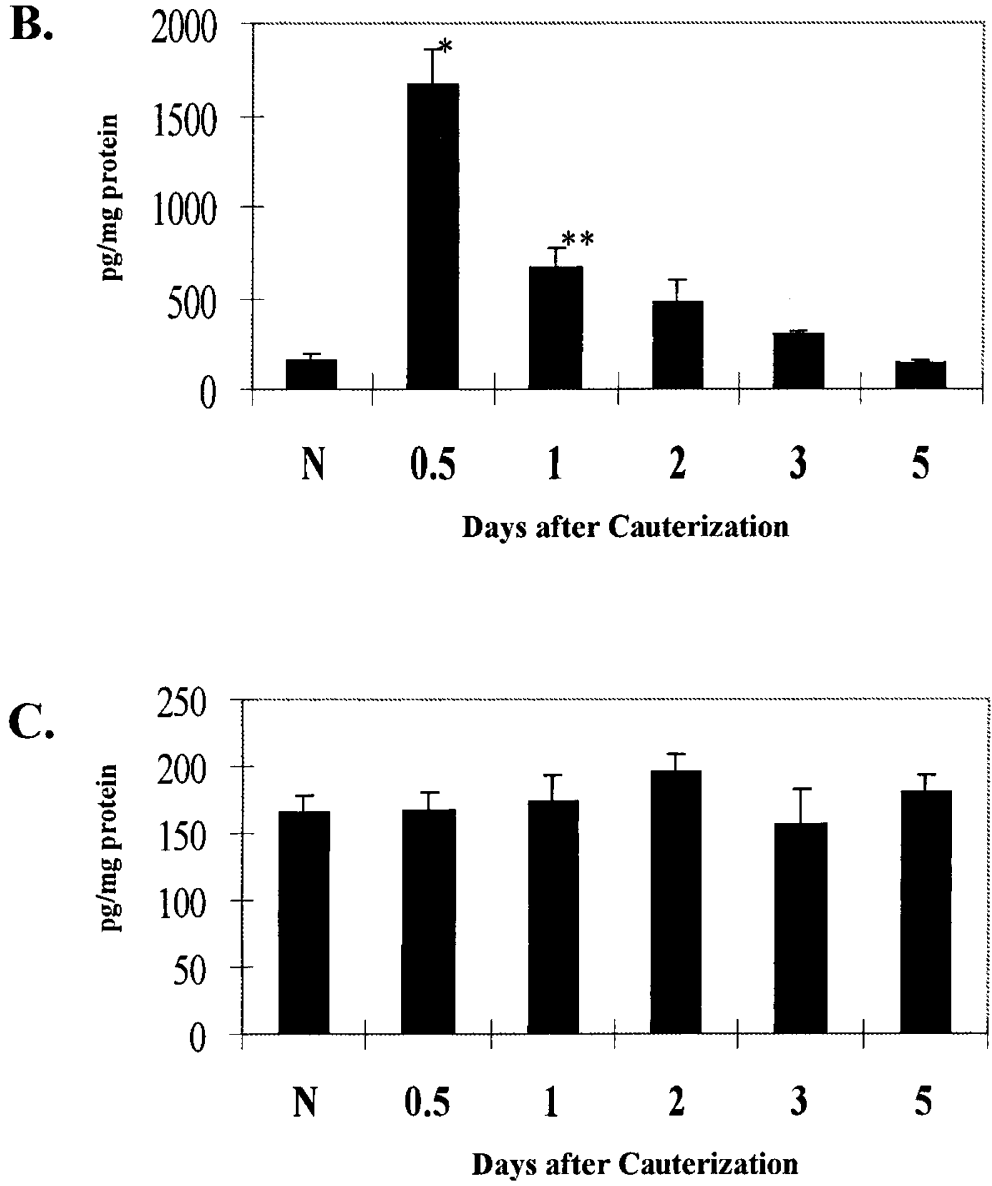

Figure 1.

Time kinetics for protein levels of monocyte chemotactic protein-1 (MCP-1) (A), IL-1 $\beta$ (B), and TNF- $\alpha$ (C) after chemical cauterization. Four corneas were removed after cauterization at the indicated time. Corneal lysates were prepared and were individually assayed by ELISA. The bars show the mean \pm SEM of four independent experiments per time point. Statistically significant differences $\left({ }^{\star} p<0.01 ;{ }^{* \star} p<0.02\right)$ compared with normal mice.

tion of PBS alone did not (Fig. 5). Both IL-1 $\beta$ and MCP-1 could thus induce angiogenesis in rat corneas in vivo.

\section{Neutralizing IL-1 $\beta$ and MCP-1 Reduces Cauterization-Induced Neovascularization}

We next determined whether neutralization of IL-1 $\beta$ and MCP-1 in the cornea-cauterization model would attenuate the angiogenic response. Passive immunization with neutralizing IL- $1 \beta$ and MCP- 1 antibodies on Days 0 and 3 led to reduced total neovascularization for both, to a similar extent as compared with control values $(29 \%$ and $28 \%$ decrease, respectively, $p<0.05$; Fig. 6). Coadministration of the two antibodies inhibited neovascularization to a slightly lager degree than single administration of each antibody 
A.

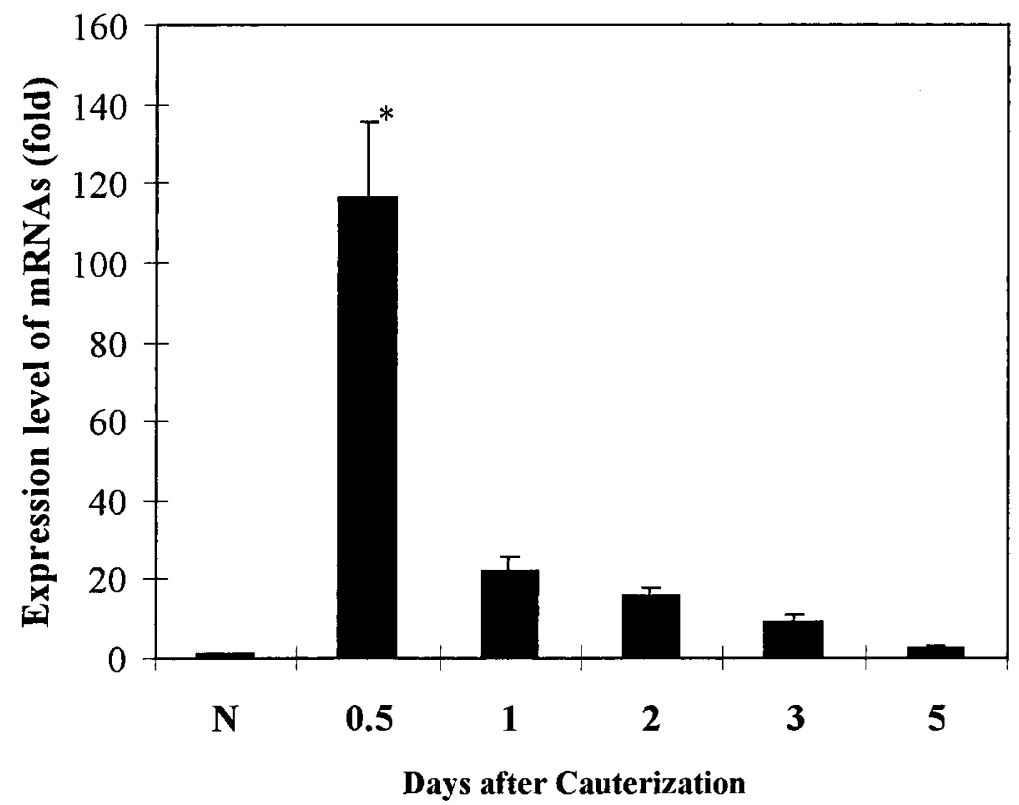

B.

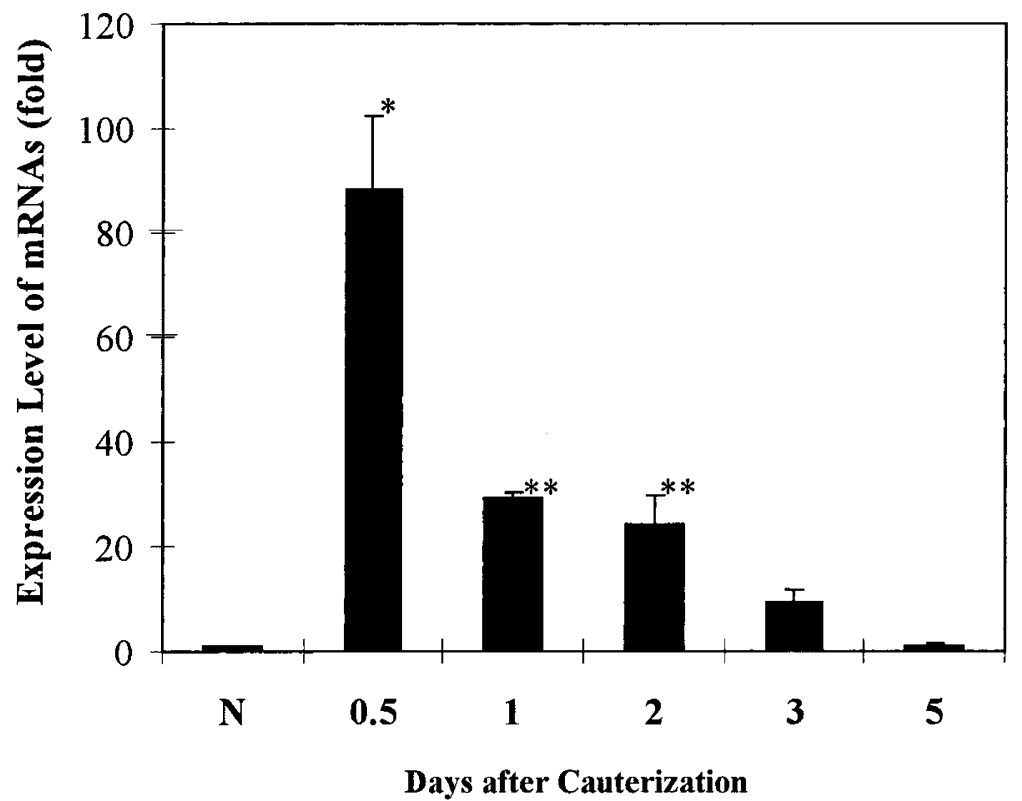

Figure 2.

Determination of the mRNA levels of MCP-1 (A) and IL-1 $\beta$ (B) by real-time quantitative RT-PCR. RNA prepared from untreated corneas and cauterized mouse corneas at indicated time points were subjected to analysis for MCP-1 and IL-1 $\beta$ mRNA. The values obtained from corneal RNA preparations of the mice at each time point have been normalized to the level of hypoxanthine guanine phosphoribosyl transferase mRNA and divided by the value of untreated control corneas. The bars show the mean \pm SEM of four independent experiments per time point. Statistically significant differences $\left({ }^{\star} p<0.01 ;{ }^{\star \star} p<0.02\right)$ compared with the normal subjects.

(35\% decrease, respectively, $p<0.05$; Fig. 6). In contrast, injections of MIP- $1 \alpha$ antibodies alone did not affect cauterization-induced corneal neovascularization (Fig. 6). Mice treated with cauterization alone had similar degree of neovascularization as control nonimmune antibody-treated mice (data not shown).
Neutralizing IL-1 $\beta$ and MCP-1 Does Not Inhibit Basic Fibroblast Growth Factor (bFGF)-Induced Corneal Neovascularization

We then examined the effect of IL-1 $\beta$ and MCP-1 neutralizing antibodies on the bFGF-driven neovascu- 


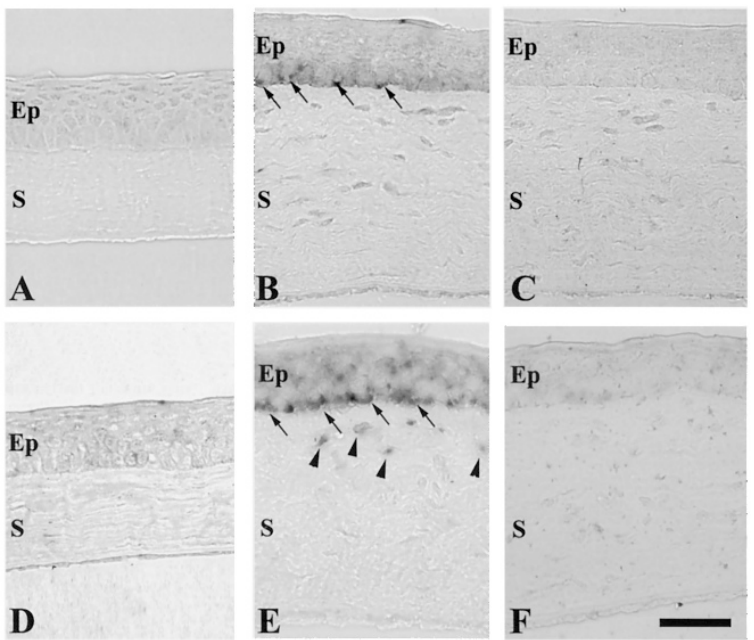

Figure 3.

Photomicrographs of in situ hybridization of a mouse cornea. Hybridization was performed with either antisense $(A, B, D$, and $E)$ or sense ( $C$ and $F)$ probes specific for MCP-1 (A to C) and IL-1 $\beta$ (D to F). A and D, Normal untreated cornea. B, C, E, and F, Cornea 12 hours after cauterization. Cornea is thickened by edema, and inflammatory cell invasion is observed in the corneal stroma. Low signal for MCP-1 mRNA is seen in an untreated cornea (A), whereas positive signals are detected in the corneal epithelia, especially in the basal cells (some of which are indicated by arrows; B). No signals are seen with MCP-1 sense probes (C). IL-1 $\beta$ mRNA is expressed weakly in untreated corneal epithelium (D). Strong signals with IL-1 $\beta$ antisense probes are detected in cauterized cornea epithelia (some of which are indicated by arrows) and in inflammatory cells (some of which are indicated by arrowheads) $(E)$, whereas no signals are seen with sense probes. $E p=$ epithelium; $S=$ stroma. Bar $=50 \mu \mathrm{m}$.

larization developed in the cornea of mice. bFGF treated with control nonimmune antibody on Days 0 and 3 induced angiogenesis strongly in an avascular area of the cornea (Fig. 7). Quantitative analysis, using six mice for each assay, showed minimal inhibition of the bFGF-induced neovascularization when anti-IL-1 $\beta$ or anti-MCP-1 were administered, although the degree of neovascularization after each antibody was slightly lower than in the control mice (Fig. 7). Mice treated with bFGF alone had a similar degree of neovascularization as control nonimmune antibodytreated mice (not shown).

\section{Depletion of MCP-1 Reduced Monocyte/Macrophage Infiltration into Cornea}

To assess the contribution of MCP-1 to monocyte/ macrophage recruitment into cornea, mice were treated with neutralizing anti-MCP-1 antibody on Days 0 and 2 after cauterization. At 3 days after cauterization, the number of monocytes/macrophages at the wound site was quantified histologically. Compared with controls, mice treated with anti-MCP-1 antibody exhibited a significant decrease in the number of monocytes/macrophages present in the wounds $(29 \%$ decrease, $p<0.05$; Fig. 8). In contrast, when compared with controls, mice treated with anti-MIP-1 $\alpha$ antibody exhibited no significant difference in the number of monocytes/macrophages present at the wound sites, although the degree of monocyte/mac- rophage density in the eyes treated with anti-MIP-1 $\alpha$ antibody was lower than in the controls (Fig. 8). Mice treated with cauterization alone had a similar density of monocytes/macrophages as control nonimmune antibody-treated mice (not shown).

\section{Discussion}

Cytokine-mediated cellular communications are thought to be of paramount importance in corneal injury and wound healing in which epithelial, stromal, and vascular endothelial cells are conjoined structurally and functionally (Wilson et al, 1999). At the site of corneal injury, a large array of monocytic chemoattractants is thought to be present (Wilson et al, 2001). We have observed a dramatic increase of MCP-1 mRNA and proteins by real-time qRT-PCR and ELISA, respectively, in response to chemical cauterization of mouse corneas (Figs. 1 and 2). Administration of anti-MCP-1, which blocked monocyte/macrophage infiltration, interfered with the inflammatory neovascularization (Figs. 6 and 8). Additionally, exogenous administration of MCP-1 into the corneal stroma induced neovascularization in the rat cornea pocket assay model (Fig. 5C). We have also observed that both MCP-1 and IL-1 $\beta$ induce neovascularization in the mouse cornea pocket model (Yoshida S, unpublished data). These observations strongly indicate that MCP-1 plays a critical role in recruiting monocytes/ macrophages and in the neovascularization in this model.

Our observations are consistent with previous reports using other inflammatory models in which the absence of MCP-1 led to a reduction in monocyte/ macrophage infiltration (Boring et al, 1998; Gosling et al, 1999; Gu et al, 1998). Recently, a direct effect of chemokines, which are not related to monocyte/macrophage recruitment, on angiogenesis has been suggested (Salcedo et al, 2000). This indicates that MCP-1 may have two independent effects in this model: enhancement of the chemotaxis of monocytic cells and stimulation of angiogenic activity. In addition, Moldovan et al (2000) recently demonstrated that cardiac overexpression of MCP-1 resulted in macrophage infiltration, which might play a role in the elaboration of new blood vessels by digging channels that become invested with endothelial progenitor cells to form capillaries. In addition to the secretion of angiogenic factors, these findings suggest another mechanism by which macrophages may participate in the elaboration of new blood vessels. Because endothelial progenitor cells make a significant contribution to corneal neovascularization (Murayama et al, 2002; Takahashi et al, 1999), similar drilling mechanisms might exist in the elaboration of new blood vessels in the inflammatory cornea.

We have previously demonstrated that MIP- $1 \alpha$, another chemokine, mediates the recruitment of monocytes/macrophages in several inflammatory diseases and is also induced during inflammatory neovascularization in the same cauterization model (Ogawa et al, 1999). Additionally, in an excisional wound repair 

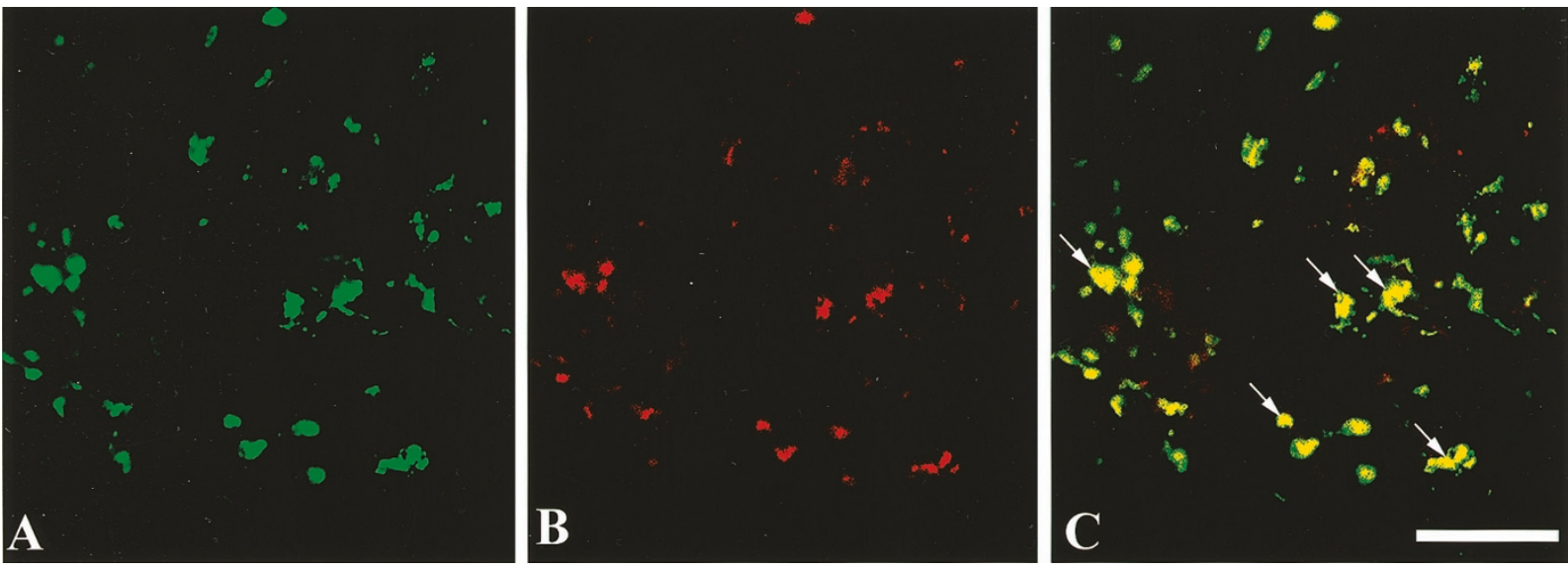

Figure 4.

Double staining for IL-1 $\beta$ and monocytes/macrophages in the cornea. A, Several monocytes/macrophages are visible after specific staining with $\mathrm{F} 4 / 80$ in the cauterized cornea 2 days after cauterization. B, Specific staining for IL-1 $\beta$ in the same section shows an identical staining pattern. C, Double staining for IL-1 $\beta$ and monocytes/macrophages in the same sample shows several positive cells for both antibodies, some of which are indicated by arrows. The yellow staining is caused by the overlapping of the red and the green colors, showing monocytes/macrophages as source for IL-1 $\beta$ in cauterized cornea. Bar $=50 \mu \mathrm{m}$.

mouse model, other researchers have reported that MIP- $1 \alpha$ plays a critical role in macrophage recruitment into wounds (DiPietro et al, 1998). Therefore, we also examined the effect of anti-MIP- $1 \alpha$ antibody on the monocyte/macrophage recruitment and neovascularization in this study. However, depletion of MIP- $1 \alpha$ by a specific antibody did not significantly change monocyte/macrophage infiltration and neovascularization, although we did observe a weak inhibitory effect of anti-MIP- $1 \alpha$ antibody on monocyte/macrophage density and neovascularization compared with the controls (Figs. 6 and 8 ). Thus, MIP- $1 \alpha$ plays a less important role than MCP-1 in this model, and the different effects of these chemokines in different inflammatory models might indicate that these chemokines exhibit their functions in a tissue-specific and environmental stress-specific manner (Low et al, 2001).

Although there are a number of cytokine systems that may participate in the responses associated with corneal injury, many investigators have suggested that the IL-1 system is especially important because it regulates many processes that are integral to the response to injury (Wilson et al, 2001). In support of this, our results demonstrated a dramatic increase of $\mathrm{IL}-1 \beta$ at both the mRNA and protein levels (Figs. 1 and $2)$, in response to cauterization. It has been thought that IL-1 $\beta$, which lacks signal sequences for transport from the cell, is constitutively expressed in the corneal epithelium and released via cell injury or death (Weng et al, 1997). We also observed basal levels of IL-1 $\beta$ expression in normal corneas (Fig. 1B), and the dramatic increase in the mRNA level of IL-1 $\beta$ after cauterization suggests that de novo synthesis may also occur. Additionally, exogenous administration of IL-1 $\beta$ into the corneal stroma induced strong neovascularization in a cornea pocket assay (Fig. 5B), and administration of anti-IL-1 $\beta$ antibody interfered with inflammatory neovascularization (Fig. 6). These findings indicate that this molecule is indeed involved in inflammatory corneal neovascularization. IL-1 $\beta$ can enhance the production of potent angiogenic factors such as IL-8 (Elner et al, 1991), vascular endothelial growth factor (Li et al, 1995), and hepatocyte growth factor (Weng et al, 1997), in addition to adhesion molecules (Beck and D'Amore, 1997; Brooks et al, 1994; Zhu and Dana, 1999) and proteases (Girard et al, 1991). Therefore, IL-1 $\beta$-dependent corneal inflammatory neovascularization might be mediated through these angiogenesis-related molecules induced by IL-1 $\beta$ itself, as secondary mediators in an autocrine/paracrine fashion. Moreover, IL-1 $\beta$ can also induce stromal edema and increase the permeability of the pericorneal and iris blood vessels, and the increased leakage and extravasation of plasma fibrinogen may aid in the formation of new extracellular matrix and contribute significantly to neovascularization. These suggestions agree well with other studies that have demonstrated that topical IL-1 receptor antagonist displays significant suppression of corneal inflammatory neovascularization (Dana et al, 1998a; Zhu and Dana, 1999).

We also examined the role of IL-1 $\beta$ and MCP-1 in corneal neovascularization driven by a more "standard" growth factor, bFGF, using the mouse cornea pocket assay model. In this well-established model, minimal inflammatory response has been reported (Kenyon et al, 1996) and we have also observed minimal monocyte/macrophage infiltration after implantation of Hydron pellets (not shown). In contrast to the contribution of IL-1 $\beta$ and MCP-1 on the inflammatory corneal neovascularization, there seemed to be little association of these molecules with bFGFdependent corneal neovascularization (Fig. 7). This indicates that distinct monocyte/macrophageinvolving angiogenic pathways exist in mouse cornea and suggest some advantages of this inflammatory corneal neovascularization model, rather than the corneal pocket model with artificial pellets, for understanding the inflammatory corneal neovascularization that may occur during pathologic development in several corneal disorders. 

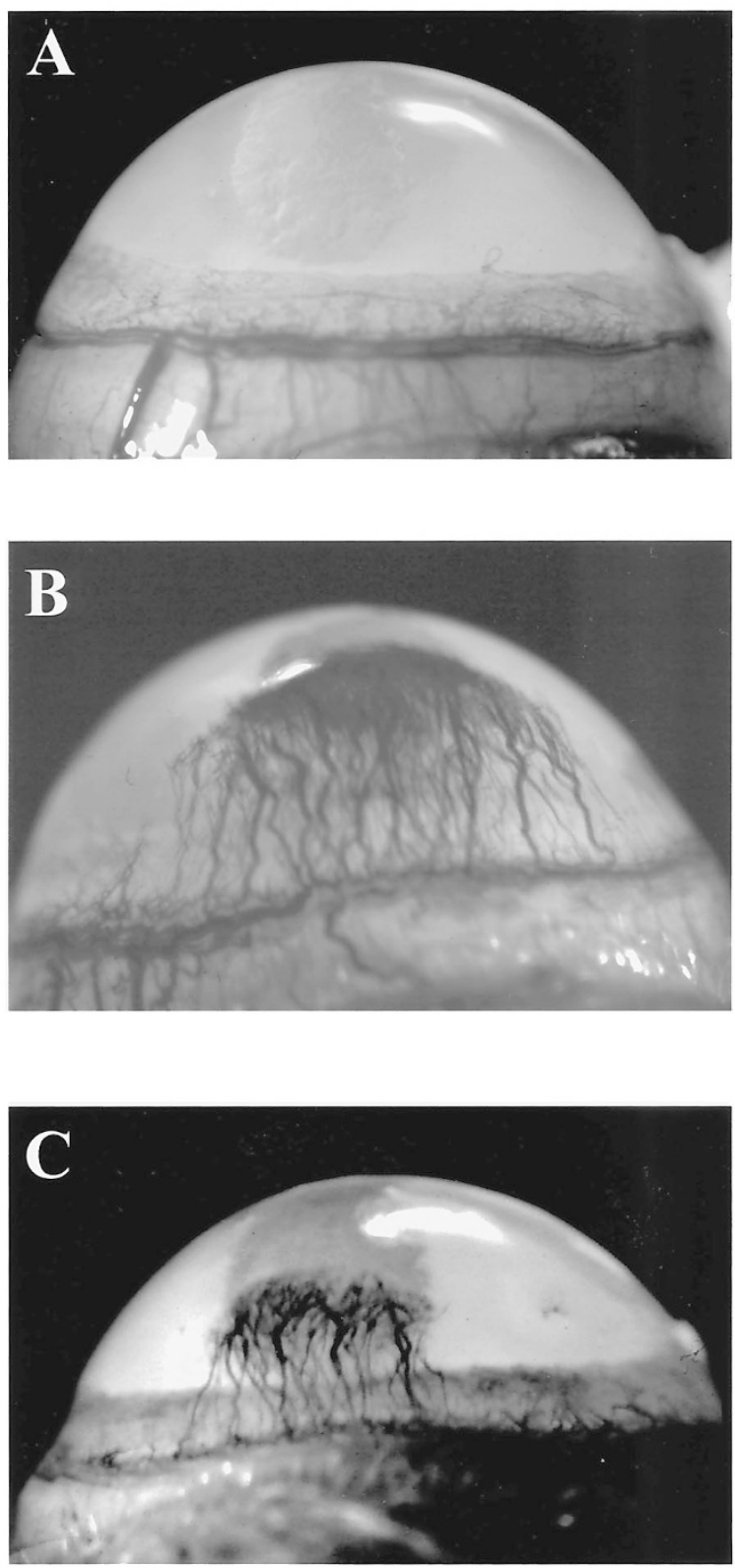

Figure 5.

The effect of IL-1 $\beta$ and MCP-1 on in vivo angiogenesis in rat cornea. Hydron pellets were formulated as described in "Materials and Methods" and implanted into rat corneas. After 6 days, vessels in the region of the pellet implant were photographed. Pellets contained (A) PBS, (B) IL-1 $\beta$, and (C) MCP-1.

The corneal epithelial tissue surface is exposed to the external environment and acts as a protective barrier (Kinoshita et al, 2001). In situ hybridization for MCP-1 and IL-1 $\beta$ showed a prominent increase in positive cells located in the basal epithelial layer of cornea at 12 hours after the cauterization (Fig. 3, B and $\mathrm{E}$ ) in comparison to the lower level of staining in the noncauterized corneas of control mice (Fig. 3, A and D). This observation suggests that the corneal epithelial cells, especially the basal cells, play an early and crucial role in the initiation of ocular surface responses after injury. Therefore, in addition to the recruited monocytes/macrophages, the corneal epi-

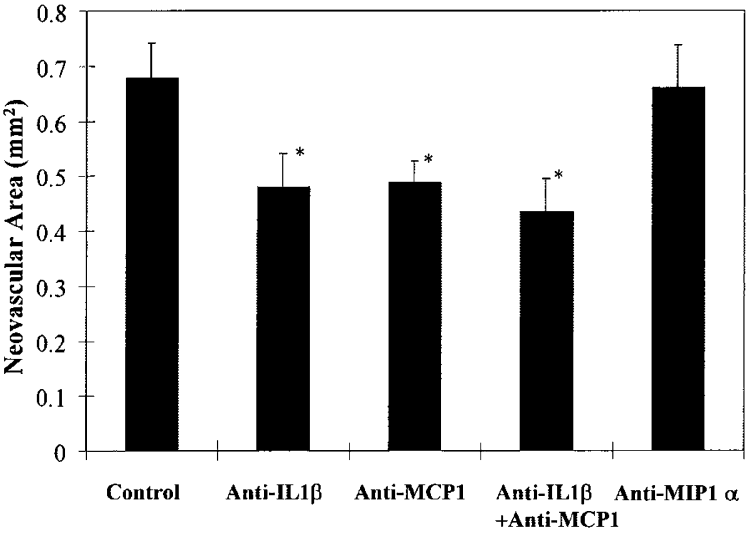

Figure 6 .

Effect of IL-1 $\beta$, MCP-1, and macrophage inflammatory protein- $1 \alpha$ (MIP-1 $\alpha$ ) neutralizing antibodies on corneal neovascularization in the cauterized cornea Mice were treated with antibody and cauterized as described in "Materials and Methods." Data are expressed as mean $\pm \operatorname{SEM}(n=6)$. * Statistically significant differences $(p<0.05)$ compared with the value obtained with the control goat antibody.

thelial cells, especially basal cells adjacent to the site of the injury, can be potential cellular targets for modulating inflammatory neovascularization in the cornea.

The modest inhibition of inflammatory corneal neovascularization by IL-1 $\beta$ and MCP- 1 neutralizing antibodies observed in this study suggests that many other stimuli (ie, soluble factors, cells, and perhaps extracellular matrix breakdown products) are important modulators of this process, and these issues must be carefully explored by a global expression profiling using state-of-the-art technologies such as DNA microarray systems (Yoshida et al, 2002). Nonetheless, our present study suggests a distinct and critical role of MCP-1 and IL- $1 \beta$ in the development of inflammatory corneal neovascularization. Because the inhibitory effect of inflammatory corneal neovascularization by coadministration of the two antibodies was not additive (Fig. 6), IL-1 $\beta$ - and MCP-1-dependent angiogenic pathways might overlap in part. Based on our study, we hypothesize that the $\mathrm{MCP}-1$ released from corneal epithelial cells around the site of injury (Fig. 3B) attracts monocytes/macrophages from peripheral blood into the cornea, where these monocytes/macrophages release IL-1 $\beta$ (Fig. 4) leading to corneal neovascularization. In parallel, IL-1 $\beta$ and MCP-1 released from corneal epithelial cells (Fig. 3, B and E) may induce corneal neovascularization irrespective of monocyte/macrophage recruitment. Our present study raises the possibility that specific molecular targeting strategies, such as the use of antibodies and/or RNA interference directed against IL-1 $\beta$ and/or MCP-1 as well as antagonists against their receptors, may eventually offer a novel approach to the management of inflammatory corneal neovascularization associated with a number of pathologic corneal states, such as chemical burn, infection, and corneal transplantation. 

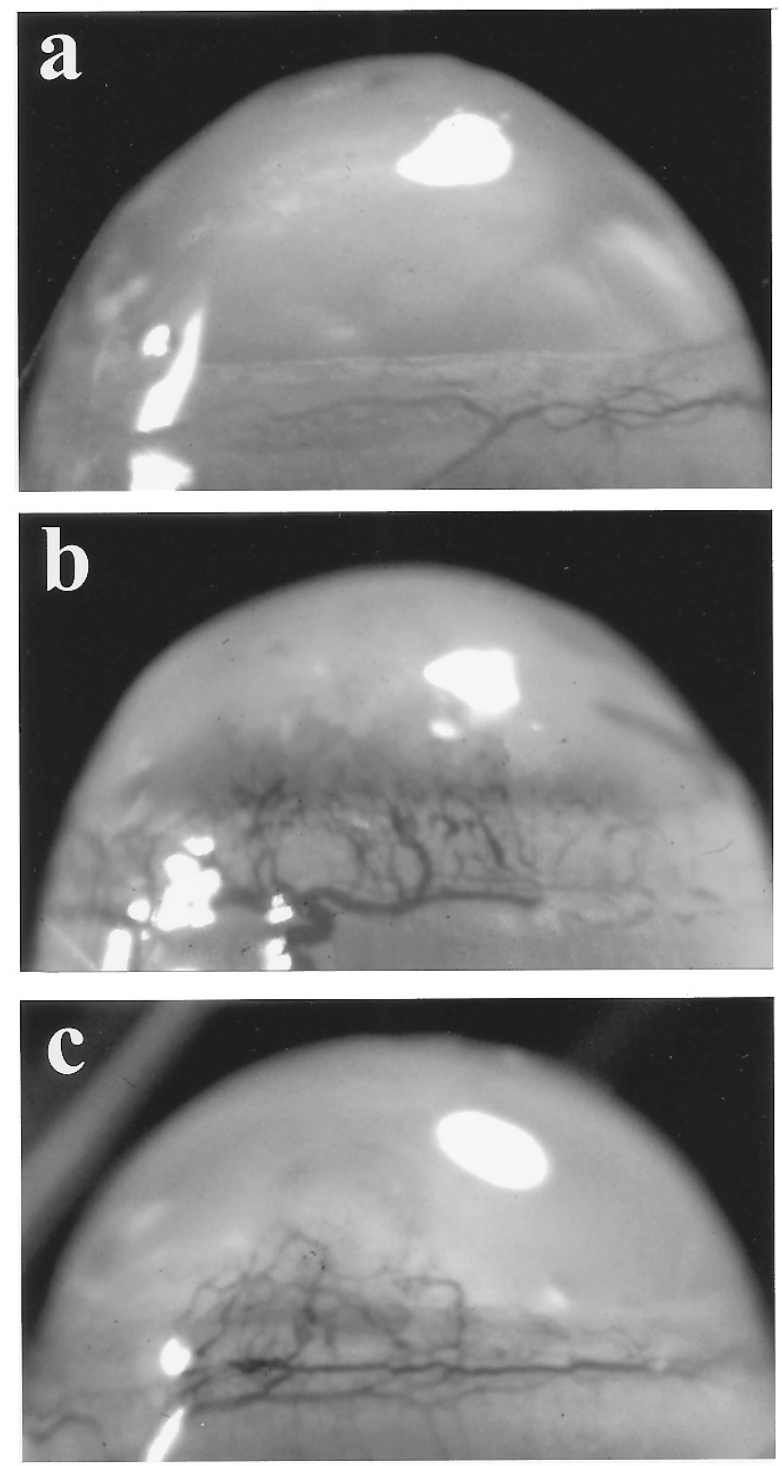

d

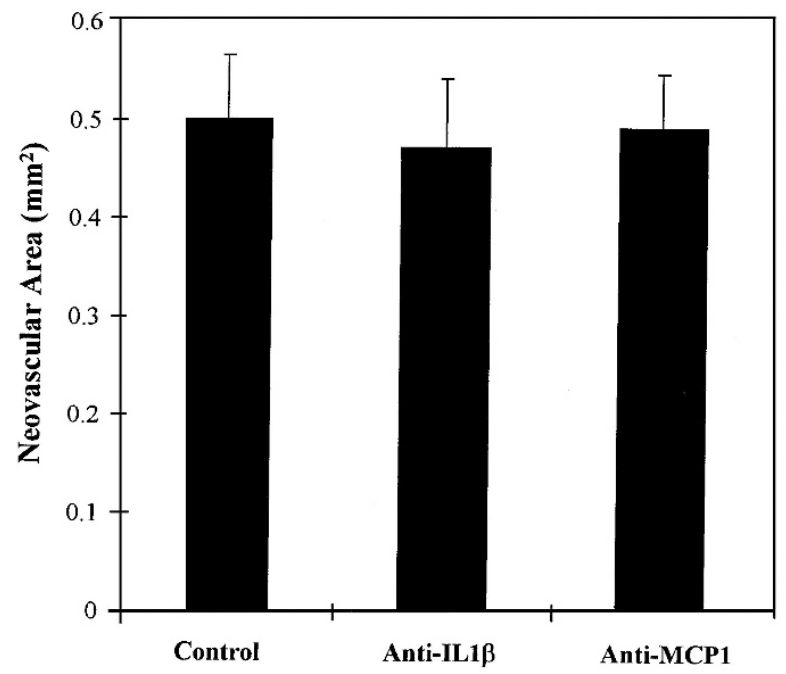

Figure 7.

Quantification of basic fibroblast growth factor (bFGF)-driven corneal neovascularization in mice. Mice were treated with control nonimmune antibody, IL-1 $\beta$ or MCP-1 neutralizing antibody, and Hydron pellets containing $50 \mathrm{ng}$ of bFGF were implanted into the corneas of BALB/c mice as described in "Materials and Methods." Six days later, vessels in the region of the pellet implant were photographed. Representative photographs of mouse corneas with Hydron pellets containing PBS alone (A), bFGF treated with control antibody (B), bFGF treated with anti-IL-1 $\beta$ antibody (C). D, Neovascular areas developed in mouse cornea were quantified as described in "Materials and Methods." Antibodies to neither IL-1 $\beta$ nor MCP-1 significantly inhibited bFGF-induced corneal neovascularization. Data are expressed as mean \pm $\operatorname{SEM}(n=6)$.

\section{Materials and Methods}

\section{Animal Model of Chemical Cauterization}

All experimental procedures on the animals were performed according to the Association for Research in Vision and Ophthalmology (ARVO) Statement for the Use of Animals in Ophthalmic and Vision Research.

Chemical cauterization was performed as previously described (Ogawa et al, 1999). Ten-week-old female BALB/c mice were deeply anesthetized by an intraperitoneal injection of $1.0 \mathrm{mg}$ of sodium pentobarbital. Corneas were cauterized with an applicator stick made up of $0.75 \mathrm{mg} / \mathrm{ml}$ silver nitrate (Nacalai Tesque, Inc., Kyoto, Japan). The tip of the applicator was applied $1 \mathrm{~mm}$ from the limbus so that a grayish- white patch (1 $\mathrm{mm}$ diameter) of cauterized tissue marked the point of contact. Erythromycin ophthalmic ointment (Santen Pharmaceutical Company, Osaka, Japan) was applied to the eye after the cauterization.

\section{ELISA}

Cytokine levels were measured using an ELISA kit for MCP-1, IL-1 $\beta$, and TNF- $\alpha$ (Biosource International, Camarillo, California) as previously described (Yoshida et al, 2003a). The sensitivities of the MCP-1, IL-1 $\beta$, and TNF- $\alpha$ were 9.0,3.0, and $3.0 \mathrm{pg} / \mathrm{ml}$, respectively. Corneas were removed from the mice at the selected times after cauterization and were individually immersed in $500 \mu \mathrm{l}$ of lysis buffer containing $20 \mathrm{~mm}$ 

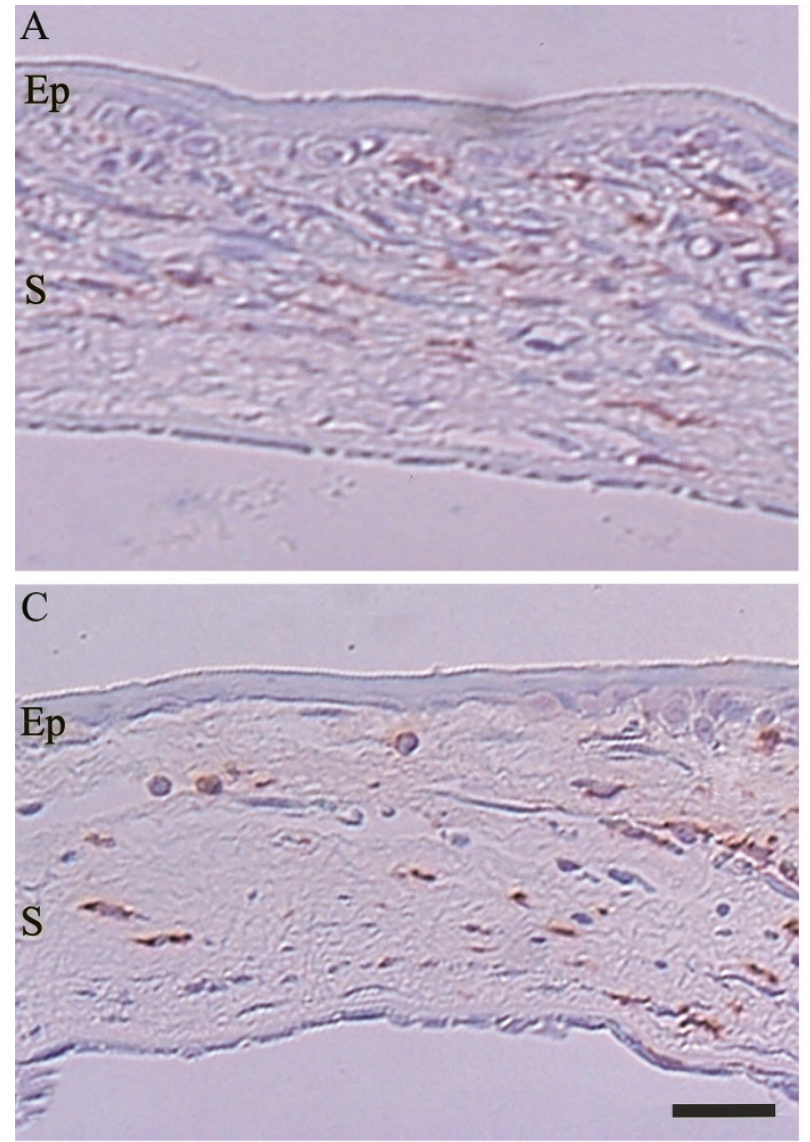
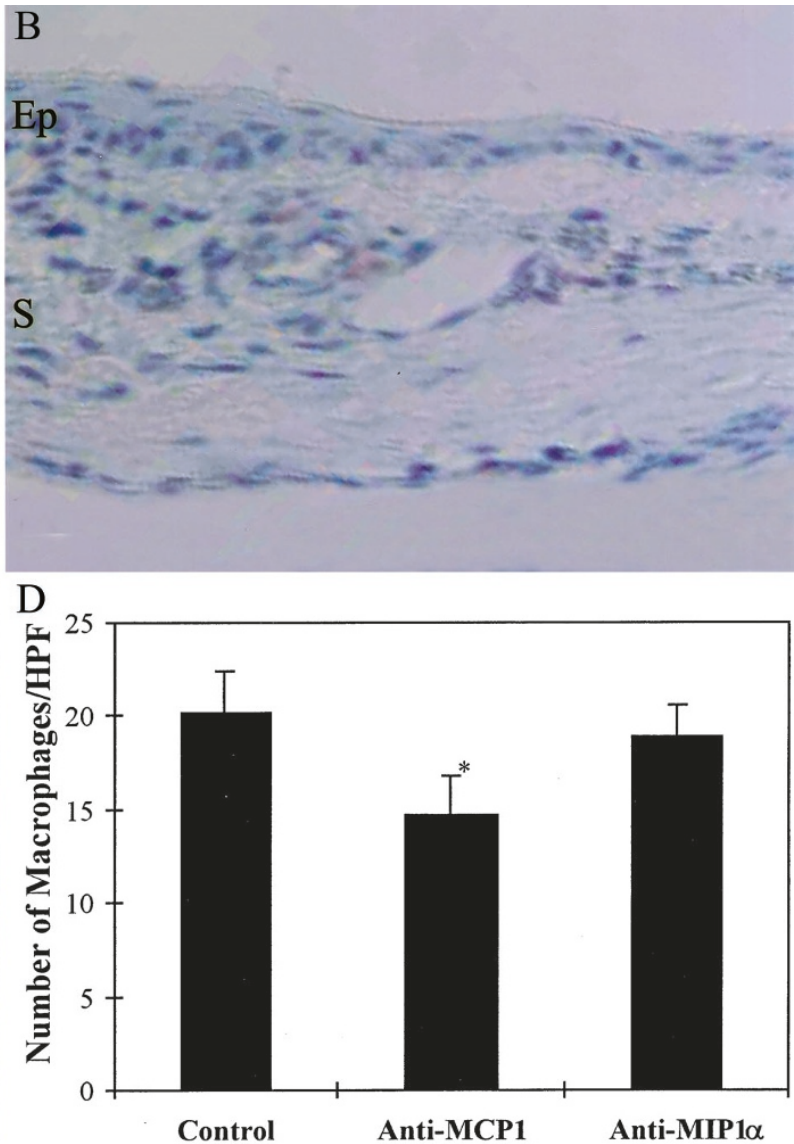

Figure 8.

Monocyte/macrophage infiltration into the wounds of mice treated with anti-MCP-1 or anti- MIP- $1 \alpha$ neutralizing antibody. Representative photomicrographs of F4/80 immunoreactivity in the cauterized cornea treated with control antibody (A), anti-MCP-1 (B), anti-MIP-1 $\alpha$ (C). Immunopositive (brown) monocytes/macrophages are seen in the corneal stroma 3 days after cauterization. $E p=$ epithelium; $S=$ stroma. Bar, $50 \mu \mathrm{m}$. D, The number of monocytes/macrophages per high power field was determined in wounds from untreated mice and mice receiving either preimmune normal goat antibody, anti-MCP-1, or anti-MIP-1 $\alpha$ neutralizing antibody. Data are expressed as mean \pm SEM $(n=6)$. ${ }^{*}$ Statistically significant differences $(p<0.05)$ compared with the value obtained with the control goat antibody.

imidazole $\mathrm{HCl}, 10 \mathrm{~mm} \mathrm{KCl}, 1 \mathrm{~mm} \mathrm{MgCl} 2,10 \mathrm{~mm}$ EGTA, $1 \%$ Triton, $10 \mathrm{~mm} \mathrm{NaF}, 1 \mathrm{~mm}$ sodium molybdate, and $1 \mathrm{~mm}$ EDTA ( $\mathrm{pH}$ 6.8) supplemented with a protease inhibitor cocktail (Roche Biomedical Systems, Indianapolis, Indiana). The corneas were pooled so that each test sample was made up of four whole corneas and were stored at $-80^{\circ} \mathrm{C}$ until use.

When used, the samples were thawed, homogenized in Polytron homogenizer (Polytron, Swiss), sonicated for 30 seconds, and clarified by centrifuging at $150 \times g$ for 10 minutes. The clarified corneal lysates were then assayed using ELISA. The total protein was determined with a commercial assay (Coomassie plus protein assay reagent kit; Pierce, Rockford, Illinois).

\section{Real-Time qRT-PCR}

Real-time qRT-PCR was performed on the purified RNAs of corneas from selected times. Total RNA was extracted from dissected mouse corneas, treated with DNase, diluted by 20 -fold in water, and subjected to reverse transcription using standard procedures. PCRs were performed with the Roche LightCycler system with a SYBR-Green Master kit (Roche Biomedical Systems). The following primer pairs were designed and used: for
MCP-1, 5'-ATCCCAATGAGTAGGCTGGAGAGC-3' and 5'-CAGAAGTGCTTGAGGTGGTTGTG-3'; for IL-1 $\beta, 5$ 'CTACGAATCTCCGACCACCACTAC-3' and 5'- GGCTTATCATCTITCAACACGCAG -3'; and for hypoxanthine guaninephosphoribosyltransferase,5'-CTACGAATCTCCGACCACCACTAC-3' and 5'- GGCTTATCATCTTTCAACACGCAG $-3^{\prime}$.

The optimal cycle programs were determined for each gene in preliminary PCR runs to obtain a single, specific PCR product as verified by melting curve analysis followed by gel electrophoresis. The cDNA quantities were calculated with the LightCycler analysis software as described previously (Morrison et al, 1998; Simpson et al, 2000). Both MCP-1 and IL-1 $\beta$ were normalized to hypoxanthine guanine phosphoribosyl transferase cDNA fragments.

\section{Generation of Riboprobes}

The cDNAs for mouse MCP- 1 and IL- $1 \beta$ were generated by RT-PCR with the same primers used for qRT-PCR. The PCR conditions were as follows: 10 minutes at $94^{\circ} \mathrm{C}$, followed by 35 cycles at $72^{\circ} \mathrm{C}$ for 20 seconds, $94^{\circ} \mathrm{C}$ for 30 seconds, and $60^{\circ} \mathrm{C}$ for 30 seconds, with a final extension step at $72^{\circ} \mathrm{C}$ for 5 
minutes. The resulting PCR fragments were subcloned into TOPO-2 (Invitrogen, San Diego, California) according to the manufacturer's protocol. Their nucleotides were sequenced, and the inserts were identified with murine $\mathrm{MCP}-1$ and $\mathrm{IL}-1 \beta$. Clones with both orientations were selected so that the same RNA polymerase (SP6) could be used to generate antisense and sense riboprobes. The templates were linearized with EcoRV, and in vitro transcription was performed using digoxigenin-labeled uridine triphosphate (Roche Biomedical Systems) according to the manufacturer's protocol.

\section{In Situ Hybridization}

Mice corneas, obtained 12 hours after cauterization, were fixed in $4 \%$ paraformaldehyde for 2 hours and embedded in paraffin. In situ hybridization was performed as described previously (Yoshida et al, 2003a). Briefly, corneas were rehydrated and treated with proteinase $\mathrm{K}$, followed by refixing in $4 \%$ paraformaldehyde in PBS for 10 minutes. The corneas were then acetylated with $0.25 \%$ acetic anhydride in $0.1 \mathrm{M}$ triethanolamine-HCL buffer $(\mathrm{pH} \mathrm{8.0)}$ for 10 minutes, dehydrated, and dried. Hybridization was performed with fresh hybridization buffer $(600 \mathrm{~mm} \mathrm{NaCl}, 10 \mathrm{~mm}$ Tris- $\mathrm{HCl}$ ( $\mathrm{pH} 7.6), 5$ mм EDTA ( $\mathrm{pH} 8.0), 1 \times$ Denhardt's solution, $50 \%$ formamide, $17 \mathrm{mg} / \mathrm{ml}$ yeast transfer RNA, and $10 \%$ weight/volume dextran) plus an approximately diluted sense or antisense digoxigeninlabeled RNA probe for 12 to 16 hours at $60^{\circ} \mathrm{C}$. After hybridization, the corneas were washed to remove nonspecifically bound RNA probe, and immunologic detection was performed by anti-digoxigenin Fab fragments conjugated to alkaline phosphatase as described in the system protocol (Roche Biomedical Systems).

\section{Double Staining for Monocytes/Macrophages and IL-1ß}

Cauterized eyes were enucleated, and the corneas were dissected from the eye. They were fixed in $4 \%$ paraformaldehyde at $4^{\circ} \mathrm{C}$ for 1 hour, with acetone for 20 minutes, incubated in PBS for 15 minutes, and blocked in normal serum for 30 minutes. The corneas were then incubated for 60 minutes at $37^{\circ} \mathrm{C}$ with rat monoclonal anti-F4/80 antibody (1:10 dilution; Biosource). After three washes with PBS, specimens were incubated with fluorescein-conjugated anti-rat IgG (Cappel, Durham, North Carolina) at room temperature for 1 hour. After three washes with PBS, specimens were placed in rabbit polyclonal anti-IL-1 $\beta$ antibody (1:100 dilution; Santa Cruz Biochemicals, Santa Cruz, California) for 1 hour at $37^{\circ} \mathrm{C}$ and then incubated with rhodamine conjugated anti-rabbit IgG (Cappel) at room temperature for 1 hour. The specimens were mounted and examined under a Leica (Wetzlar, Germany) fluorescence microscope. For negative controls, rat and rabbit nonimmune IgG was used as the primary antibody.

\section{Corneal Pocket Assay}

The rat or mouse corneal assay was performed essentially as described (Yoshida et al, 1997, 1998, 2003b). Briefly, 5- $\mu$ l Hydron pellets (Interferon Sciences, New Brunswick, New Jersey) containing mouse MCP-1 or IL-1 $\beta$ (R\&D Systems, Minneapolis, Minnesota) were implanted into the cornea of anesthetized male Sprague-Dawley rats. For mouse corneal assay, 0.3- $\mu$ l Hydron pellets containing mouse bFGF were prepared and implanted in the corneas of male $\mathrm{BALB} / \mathrm{c}$ mice. After 6 days, the animals were killed and the corneal vessels were photographed. Six rats or mice were used to assess the effect of each molecule.

\section{Subconjunctival Inoculations}

Injections of antibodies were performed by using a 33-gauge needle to penetrate the perivascular region of the conjunctiva and delivering $3 \mu$ into the subconjunctival space. Injections were performed 1 hour before cauterization or implantation of bFGFcontaining Hydron pellets and 2 or 3 days after cauterization or implantation. The concentration of goat anti-MCP-1, IL-1 $\beta$, MIP- $1 \alpha$, and control nonimmune IgG (R\&D Systems) administered was $10 \mu \mathrm{g} / \mu \mathrm{l}$.

\section{Quantification of Corneal Neovascularization}

Photographs were taken using Fuji Ektachrome film (Fuji Photo Film Company, Tokyo, Japan) on the fifth (for the cauterization) or sixth (for pellet implantation) postoperative day using a scale and the same magnification. Images of the corneas were scanned using Nikon Coolscan software (Nikon Company, Tokyo, Japan) with standardized illumination, contrast, and threshold settings, and were saved on disk as Tag image file format (TIFF). The areas of corneal neovascularization were analyzed with the National Institutes of Health Image 1.61 software package (http:// rsb.info.nih.gov/nih-image). The areas are expressed in square millimeter.

\section{Quantification of Monocyte/Macrophage Infiltration}

To quantify the degree of monocyte/macrophage infiltration, 3- $\mu \mathrm{m}$ sections of the eyes were cut, and after removal of paraffin and rehydration, the sections were incubated with rat polyclonal anti-mouse F4/80 (1:13 dilution) for 1 hour at room temperature. Bound antibodies were detected by the conventional avidinbiotin-peroxidase protocol (Yoshida et al, 1999b), with 3-amino-9-ethylcarbazole as substrate. For negative controls, rat nonimmune $\lg G$ was used as the primary antibody.

In each case, a brief scan was made of the entire section at low power, and then the monocyte/macrophage infiltration was assessed microscopically three times by a masked observer. The number of monocytes/macrophages per microscopic field ( $\times 400$ magnification) was recorded for four to six sections for each mouse. 


\section{Statistical Analysis}

Data were analyzed by one-way ANOVA followed by Bonferroni $t$ test. Results are reported as the means \pm SEM.

\section{References}

Amano S, Rohan R, Kuroki M, Tolentino M, and Adamis AP (1998). Requirement for vascular endothelial growth factor in wound- and inflammation-related corneal neovascularization. Invest Ophthalmol Vis Sci 39:18-22.

Beck L Jr and D'Amore PA (1997). Vascular development: Cellular and molecular regulation. FASEB J 11:365-373.

BenEzra D, Hemo I, and Maftzir G (1990). In vivo angiogenic activity of interleukins. Arch Ophthalmol 108:573-576.

Boring L, Gosling J, Cleary M, and Charo IF (1998). Decreased lesion formation in $\mathrm{CCR} 2^{-1-}$ mice reveals a role for chemokines in the initiation of atherosclerosis. Nature 394: 894-897.

Brooks PC, Clark RA, and Cheresh DA (1994). Requirement of vascular integrin alpha $v$ beta 3 for angiogenesis. Science 264:569-571.

Chang JH, Gabison EE, Kato T, and Azar DT (2001). Corneal neovascularization. Curr Opin Ophthalmol 12:242-249.

Coxon A, Bolon B, Estrada J, Kaufman S, Scully S, Rattan A, Duryea D, Hu YL, Rex K, Pacheco E, Van G, Zack D, and Feige $U$ (2002). Inhibition of interleukin-1 but not tumor necrosis factor suppresses neovascularization in rat models of corneal angiogenesis and adjuvant arthritis. Arthritis Rheum 46:2604-2612.

Crowther M, Brown NJ, Bishop ET, and Lewis CE (2001). Microenvironmental influence on macrophage regulation of angiogenesis in wounds and malignant tumors. J Leukoc Biol 70:478-490.

Dana MR, Dai R, Zhu S, Yamada J, and Streilein JW (1998a). Interleukin-1 receptor antagonist suppresses Langerhans cell activity and promotes ocular immune privilege. Invest Ophthalmol Vis Sci 39:70-77.

Dana MR, Zhu SN, and Yamada J (1998b). Topical modulation of interleukin-1 activity in corneal neovascularization. Cornea 17:403-409.

DiPietro LA, Burdick M, Low QE, Kunkel SL, and Strieter RM (1998). MIP-1alpha as a critical macrophage chemoattractant in murine wound repair. J Clin Invest 101:1693-1698.

Edelman JL, Castro MR, and Wen Y (1999). Correlation of VEGF expression by leukocytes with the growth and regression of blood vessels in the rat cornea. Invest Ophthalmol Vis Sci 40:1112-1123.

Elner VM, Strieter RM, Pavilack MA, Elner SG, Remick DG, Danforth JM, and Kunkel SL (1991). Human corneal interleukin-8: IL-1 and TNF-induced gene expression and secretion. Am J Pathol 139:977-988.

Epstein RJ, Stulting RD, Hendricks RL, and Harris DM (1987). Corneal neovascularization: Pathogenesis and inhibition. Cornea 6:250-257.

Fahey TJ 3rd, Sherry B, Tracey KJ, van Deventer S, Jones WG 2nd, Minei JP, Morgello S, Shires GT, and Cerami A (1990). Cytokine production in a model of wound healing: The appearance of MIP-1, MIP-2, cachectin/TNF and IL-1. Cytokine 2:92-99.
Gan L and Fagerholm P (2001). Leukocytes in the early events of corneal neovascularization. Cornea 20:96-99.

Girard MT, Matsubara M, and Fini ME (1991). Transforming growth factor-beta and interleukin-1 modulate metalloproteinase expression by corneal stromal cells. Invest Ophthalmol Vis Sci 32:2441-2454.

Goede V, Brogelli L, Ziche M, and Augustin HG (1999). Induction of inflammatory angiogenesis by monocyte chemoattractant protein-1. Int J Cancer 82:765-770.

Gosling J, Slaymaker S, Gu L, Tseng S, Zlot CH, Young SG, Rollins BJ, and Charo IF (1999). MCP-1 deficiency reduces susceptibility to atherosclerosis in mice that overexpress human apolipoprotein B. J Clin Invest 103:773-778.

Gu L, Okada Y, Clinton SK, Gerard C, Sukhova GK, Libby P, and Rollins BJ (1998). Absence of monocyte chemoattractant protein-1 reduces atherosclerosis in low density lipoprotein receptor-deficient mice. Mol Cell 2:275-281.

Kenyon BM, Voest EE, Chen CC, Flynn E, Folkman J, and D'Amato RJ (1996). A model of angiogenesis in the mouse cornea. Invest Ophthalmol Vis Sci 37:1625-1632.

Kinoshita S, Adachi W, Sotozono C, Nishida K, Yokoi N, Quantock AJ, and Okubo K (2001). Characteristics of the human ocular surface epithelium. Prog Retin Eye Res 20: $639-673$.

Klintworth GK and Burger PC (1983). Neovascularization of the cornea: Current concepts of its pathogenesis. Int Ophthalmol Clin 23:27-39.

Kunkel SL (1999). Through the looking glass: The diverse in vivo activities of chemokines. J Clin Invest 104:1333-1334.

Le $\mathrm{J}$ and Vilcek $\mathrm{J}$ (1987). Tumor necrosis factor and interleukin 1: Cytokines with multiple overlapping biological activities. Lab Invest 56:234-248.

Lewis JS, Landers RJ, Underwood JC, Harris AL, and Lewis CE (2000). Expression of vascular endothelial growth factor by macrophages is up-regulated in poorly vascularized areas of breast carcinomas. J Pathol 192:150-158.

Li J, Perrella MA, Tsai JC, Yet SF, Hsieh CM, Yoshizumi M, Patterson C, Endege WO, Zhou F, and Lee ME (1995). Induction of vascular endothelial growth factor gene expression by interleukin-1 beta in rat aortic smooth muscle cells. J Biol Chem 270:308-312.

Low QE, Drugea IA, Duffner LA, Quinn DG, Cook DN, Rollins BJ, Kovacs EJ, and DiPietro LA (2001). Wound healing in MIP-1alpha(-/-) and MCP-1(-/-) mice. Am J Pathol 159: 457-463.

Moldovan NI, Goldschmidt-Clermont PJ, Parker-Thornburg J, Shapiro SD, and Kolattukudy PE (2000). Contribution of monocytes/macrophages to compensatory neovascularization: The drilling of metalloelastase-positive tunnels in ischemic myocardium. Circ Res 87:378-384.

Moromizato Y, Stechschulte S, Miyamoto K, Murata T, Tsujikawa A, Joussen AM, and Adamis AP (2000). CD18 and ICAM-1-dependent corneal neovascularization and inflammation after limbal injury. Am J Pathol 157:1277-1281.

Morrison TB, Weis JJ, and Wittwer CT (1998). Quantification of low-copy transcripts by continuous SYBR Green I monitoring during amplification. Biotechniques 24:954-958, 960: 962. 
Murayama T, Tepper O, Silver M, Ma H, Losordo D, Isner J, Asahara T, and Kalka C (2002). Determination of bone marrow-derived endothelial progenitor cell significance in angiogenic growth factor-induced neovascularization in vivo. Exp Hematol 30:967.

Ogawa S, Yoshida S, Ono $\mathrm{M}$, Onoue $\mathrm{H}$, Ito $\mathrm{Y}$, Ishibashi $\mathrm{T}$, Inomata H, and Kuwano M (1999). Induction of macrophage inflammatory protein-1alpha and vascular endothelial growth factor during inflammatory neovascularization in the mouse cornea. Angiogenesis 3:327-334.

Polverini PJ, Cotran PS, Gimbrone MA Jr, and Unanue ER (1977). Activated macrophages induce vascular proliferation. Nature 269:804-806.

Salcedo R, Ponce ML, Young HA, Wasserman K, Ward JM, Kleinman HK, Oppenheim JJ, and Murphy WJ (2000). Human endothelial cells express CCR2 and respond to MCP-1: Direct role of MCP-1 in angiogenesis and tumor progression. Blood 96:34-40.

Simpson DA, Feeney S, Boyle C, and Stitt AW (2000). Retinal VEGF mRNA measured by SYBR green I fluorescence: A versatile approach to quantitative PCR. Mol Vis 6:178-183.

Sotozono C, He J, Matsumoto Y, Kita M, Imanishi J, and Kinoshita S (1997). Cytokine expression in the alkali-burned cornea. Curr Eye Res 16:670-676.

Strieter RM, Standiford TJ, Huffnagle GB, Colletti LM, Lukacs NW, and Kunkel SL (1996). The good, the bad, and the ugly: The role of chemokines in models of human disease. $\mathrm{J} \mathrm{Im}$ munol 156:3583-3586.

Sunderkotter C, Beil W, Roth J, and Sorg C (1991). Cellular events associated with inflammatory angiogenesis in the mouse cornea. Am J Pathol 138:931-939.

Sunderkotter C, Steinbrink K, Goebeler M, Bhardwaj R, and Sorg C (1994). Macrophages and angiogenesis. J Leukoc Biol 55:410-422.

Takahashi T, Kalka C, Masuda H, Chen D, Silver M, Kearney M, Magner M, Isner JM, and Asahara T (1999). Ischemia- and cytokine-induced mobilization of bone marrow-derived endothelial progenitor cells for neovascularization. Nat Med 5:434-438.

Weng J, Mohan RR, Li Q, and Wilson SE (1997). IL-1 upregulates keratinocyte growth factor and hepatocyte growth factor mRNA and protein production by cultured stromal fibroblast cells: Interleukin-1 beta expression in the cornea. Cornea 16:465-471.
Wilson SE, Liu JJ, and Mohan RR (1999). Stromal-epithelial interactions in the cornea. Prog Retin Eye Res 18:293-309.

Wilson SE, Mohan RR, Ambrosio R Jr, Hong J, and Lee J (2001). The corneal wound healing response: Cytokinemediated interaction of the epithelium, stroma, and inflammatory cells. Prog Retin Eye Res 20:625-637.

Yoshida A, Yoshida S, Hata Y, Khalil AK, Ishibashi T, and Inomata H (1998). The role of NF-kappaB in retinal neovascularization in the rat: Possible involvement of cytokineinduced neutrophil chemoattractant (CINC), a member of the interleukin-8 family. J Histochem Cytochem 46:429-436.

Yoshida A, Yoshida S, Ishibashi T, and Inomata H (1999a). Intraocular neovascularization. Histol Histopathol 14:12871294.

Yoshida A, Yoshida S, Ishibashi T, Kuwano M, and Inomata $H$ (1999b). Suppression of retinal neovascularization by the NF-kappaB inhibitor pyrrolidine dithiocarbamate in mice. Invest Ophthalmol Vis Sci 40:1624-1629.

Yoshida S, Ono M, Shono T, Izumi H, Ishibashi T, Suzuki H, and Kuwano M (1997). Involvement of interleukin-8, vascular endothelial growth factor, and basic fibroblast growth factor in tumor necrosis factor alpha-dependent angiogenesis. Mol Cell Biol 17:4015-4023.

Yoshida S, Yashar BM, Hiriyanna S, and Swaroop A (2002). Microarray analysis of gene expression in the aging human retina. Invest Ophthalmol Vis Sci 43:2554-2560.

Yoshida S, Yoshida A, Ishibashi T, Elner SG, and Elner VM (2003a). Role of MCP-1 and MIP-1alpha in retinal neovascularization during postischemic inflammation in a mouse model of retinal neovascularization. J Leukoc Biol 73:137144.

Yoshida S, Yoshida A, Ishibashi T, Kumano Y, and Matsui T (2003b). Presence of vitronectin in neovascularized cornea of patient with gelatinous drop-like dystrophy. $\mathrm{Br} \mathrm{J}$ Ophthalmol 87:368-369.

Zhang H, Li C, and Baciu PC (2002). Expression of integrins and MMPs during alkaline-burn-induced corneal angiogenesis. Invest Ophthalmol Vis Sci 43:955-962.

Zhu SN and Dana MR (1999). Expression of cell adhesion molecules on limbal and neovascular endothelium in corneal inflammatory neovascularization. Invest Ophthalmol Vis Sci 40:1427-1434. 